\title{
CONSUMER AWARENESS AND ATTITUDES TOWARDS ACTIVE AND INTELLIGENT PACKAGING SYSTEMS IN THE LATVIAN MARKET
}

\author{
Vjaceslavs Kocetkovs*, Sandra Muizniece-Brasava, Asnate Kirse-Ozolina \\ Department of Food Technology, Faculty of Food Technology, Latvia University of Life Sciences and Technologies, \\ Rigas iela 22, Jelgava, Latvia, e-mail: kvsxc70@gmail.com
}

\begin{abstract}
Packaging is designed to preserve foods against damage and contamination and prolong storage time. It provides isolation (product hold), protection (quality, safety, freshness), information (graphics, labels) and usefulness or convenience. However, packaging offers much more than these benefits for the manufacturer and the consumer. Changes in consumer preference for safe food have led to innovation in packaging technologies. Active and intelligent packaging is a packaging technology which offers to deliver safe and qualitative products. Active packaging refers to the inclusion of components in the package in order to maintain or extend the quality and shelf life of the product. Intelligent systems are those that monitor the state of packaged food to provide information on the quality of packaged food during transportation and storage. These technologies are designed to increase the demand for safer foods that provide better shelf life. The market for active and intelligent packaging systems is expected to have a promising future by integrating them into packaging materials or systems. A survey was conducted to study consumer awareness and attitudes towards active and intelligent packaging and their introduction in the Latvian market. 865 respondents from different regions of Latvia answered 19 questions on how well they were informed about smart packaging, how much they would be willing to pay for it, as well as an analysis of consumer confidence about the impact of smart packaging on product quality during storage. The results show that the majority of respondents have insufficient knowledge and understanding about smart packaging.
\end{abstract}

Keywords: active packaging, intelligent packaging, shelf life, consumers, market

\section{Introduction}

Packaging is a protective shell that protects the product from shocks, dirt, heat, light, bacteria and other external factors. It has many functions including the protection of unprocessed or processed foods against contamination and other risks posed by the external environment (Omanovic-Mikličanin, 2017). Packaging serves as an obstacle to potentially harmful access of light, oxygen and water. It facilitates use, offers longterm storage, analyses and transfers information on the product and possible deterioration (Marsh, Bugusu, 2007). Packaging achieves the following means (Robertson, 2006):

$\circ$ limiting colour, taste, odour, texture changes and other damage to food products;

o preventing threats of biological, chemical or physical damage;

- controlling the absorption and loss of $\mathrm{O}_{2}$ and water vapours;

- facilitating the use of product content, such as packaging containing combined products, "meal kits";

0 avoiding manipulation of content and using labels that are safe;

0 providing information on ingredients, dietary doses, manufacturer's name and address, product weight, barcode information and packaging labelling.

Marketing packaging standards include some specialised trademarks that should be recognized by the processor and available worldwide. Such packages can boost sales. They can be firm, flexible, metalized etc., and can contain information such as trade reports, health reports, recipes or coupons (Schafera, Cheungb, 2018). The key safety objective for traditional packaging materials which come in contact with food is to be as inert as possible. While the smart packaging systems as active and intelligent packaging concepts are based on the useful interaction between packaging environment and the food, it also needs to provide active protection of the food (Kuswandi et al., 2011).

Active packaging is the first alternative to traditional packaging methods. It refers to an innovative foodpackaging concept introduced in response to continuous changes in consumer demands and market trends. Active packaging technology embeds components into the packaging that can release or absorb substances from or into the preserved food or the surrounding environment to sustain quality and prolong shelf life (Arvanitoyannis, Stratakos, 2012). The components frequently used in active packaging systems include oxygen scavengers, ethylene scavengers, flavour and odour absorbers/releasers, antimicrobials and antioxidants (Prasad, Kochhar, 2014). Advantages of using active packaging for perishable goods include reduction of the amount of active substances, reduction of localisation activity and migration of particles from film to food, and elimination of unnecessary industrial processes that might introduce bacteria into the product (Bolumar et al., 2011).

Intelligent packaging systems use communication functions to facilitate decision-making aimed at preserving food quality, extending shelf life and improving overall food safety (Ghaani et al., 2016). Intelligent packaging is mainly used to monitor the condition of packaged foods in order to gather and provide information on the quality of the packaged good during transport and storage (Kerry et al., 2006). It can carry out intelligent functions such as sensing, detecting, and tracing, recording and communicating certain types of information (Realini, Marcos, 2014). Accordingly, intelligent packaging systems consist of hardware components such as time temperature indicators, gas detectors, freshness and/or ripening indicators (Prasad, Kochhar, 2014) and radio frequency identification 
(RFID) systems (Kerry et al., 2006). The required functions can be implemented and realized via indicators and sensor devices to communicate the pertinent information. Indicators inform about a detected change in a product or its environment, for example a change in temperature or $\mathrm{pH}$ level (Yam et al., 2005). In food packaging, this technology is often complemented with biosensors to detect, record and transmit information related to potential biological processes and reactions occurring inside the package, for example changes in oxygen and freshness levels (Yam et al., 2005; Ghaani et al., 2016).

Traditional food packaging is mainly petroleum-based plastics. The main risks and concerns of traditional food packaging production and applications are related to non-sustainable production, insufficient mechanical and barrier properties, lack of recyclability. In addition, these materials are not biodegradable. The main challenges faced by many food producers are weak barrier properties to water vapour and gases, and achieving an adequate shelf-life for food products (Mihindukulasuriya, Lim, 2014). Active and intelligent packaging plays a major role in filling the gaps of traditional packaging by positively affecting the shelflife, safety, quality, security of food which is very important for the consumers and producers. Active and intelligent packaging at this moment present a total packaging concept, which includes nanoparticle application in more production phases. Risk, which is associated with nanoparticle application, is their migration into to the food that can potentially result in adverse health effects (Echegoyen, Nerin, 2013). However, not all innovative food technologies get equal acceptance by consumers (Siegrist, 2008).

The aim of this study was to assess consumer awareness and attitudes towards active and intelligent packaging and their introduction in the Latvian market.

\section{Materials and Methods}

\section{Poll participants}

The survey was conducted with 865 respondents (around 170 persons for each region) who live in different regions to represent the whole population of Latvia as closely as possible. The methodology of questionnaire was used to achieve the research objectives. The questionnaire contained 19 multiplechoice questions and was distributed to respondents using an online survey website VisiDati.lv. The distribution of respondents by sex was $65.9 \%$ female and $44.1 \%$ male. Most respondents (46.5\%) were between the ages of 17 and 29, 40.7\% were between the ages of 30 and 50, and $12.8 \%$ were over 50 years old. In response to educational status, majority of those who participated in the survey indicated that they had a master's or a bachelor's degree $-57.0 \% ; 20.6 \%$ of the respondents held a technical degree. Degree for high school, associate and graduate were $17.4 \%$. The survey provided an analysis of respondents living in the following regions of Latvia: Riga, Zemgale, Vidzeme, Latgale, Kurzeme.

\section{Data processing}

Data processing was performed using MS Excel v16 software. Significant differences $(p<0.05)$ were established by one-way analysis of variance (ANOVA).

\section{Results and Discussion}

The survey provided the analysis of respondents in order to clarify the consumer attitudes and knowledge about packaging. Most respondents believe that they will use a lot of packaging, which makes it possible to conclude that the customer is ready for change. A similar situation was illustrated in a study by Irish scientists (O' Callaghan, Kerry, 2016).

The survey results showed that respondents have a poor knowledge of intelligent packaging (Figure 1), as only $12 \%$ understood the term "smart", while more than a half of respondents in Latvia and its regions generally do not understand the term intelligent packaging. In the study by Irish scientists (O' Callaghan, Kerry, 2016) nanotechnology gained the highest level of awareness compared to active and intelligent packaging which received lower levels of recognition.

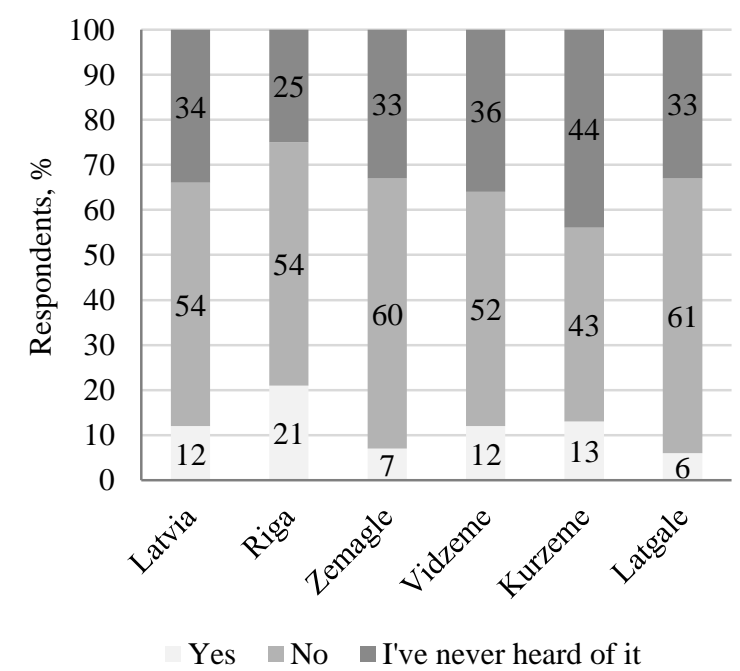

Figure 1. Consumer understanding on what the term "smart packaging" means

The study of Canadian scientists (Chen et al., 2013) showed that the market success of food innovations depends on the consumers' perceptions of the technologies. It is therefore important to educate consumers. Participants from Turkey pointed out that advertising through advertising $(40.55 \%)$ would be the most effective way to increase the overall acceptability of innovative packages (Aday, Yener, 2015).

Figure 2 shows the ability of respondents to distinguish between active and intelligent packaging. More than $60 \%$ respondents on average cannot distinguish between active and intelligent packaging. It is important that a relatively large proportion of respondents $(28 \%$ on average in Latvia) are not interested; it shows that consumers should be more intensively informed about the benefits of active and intelligent packaging. 


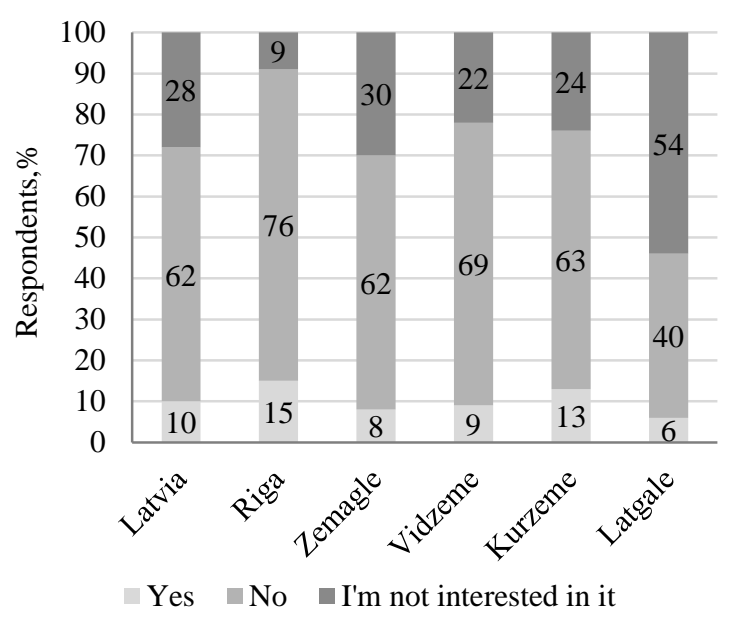

Figure 2. Respondents' ability to distinguish between active and intelligent packaging

As the range of differently packaged food products on the shelves of Latvia's supermarkets is wide and different packaging solutions are used, the question is whether consumers see the products packed in smart packaging on supermarket shelves (Figure 3).

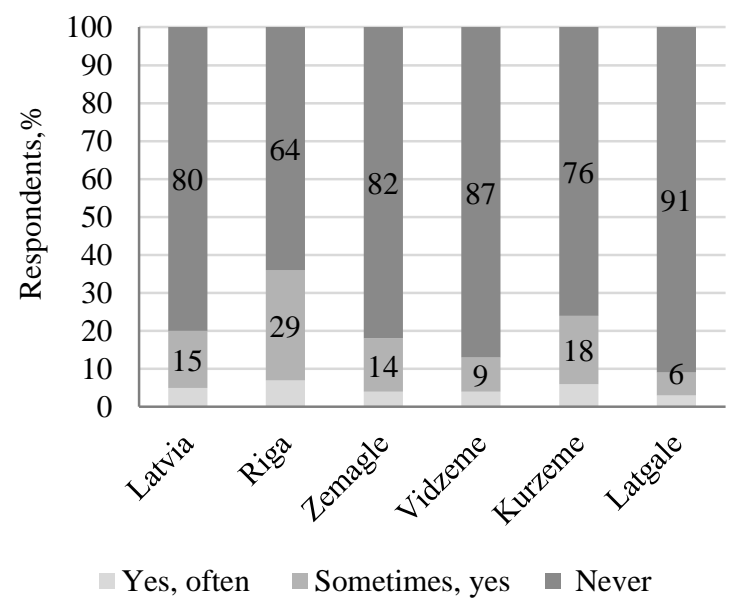

Figure 3. Visibility of intelligent packaging on supermarket shelves

Although there are products packed in smart packaging in supermarkets in Latvia, 80\% (in Latvia in general) have not seen such smart packaging solutions on supermarket shelves. The most positive responses on this issue have been provided by respondents in Riga (36\%), which could be explained by a denser number of supermarkets in Riga compared to the regions, as well as more information on innovations available in the capital. Analysing the data in Figures 2 and 3, it can be concluded that the consumer is currently very unaware of the new technologies in smart packaging. Consequently, consumers do not orient themselves and cannot distinguish between smart packaging that includes active packaging and intelligent packaging.

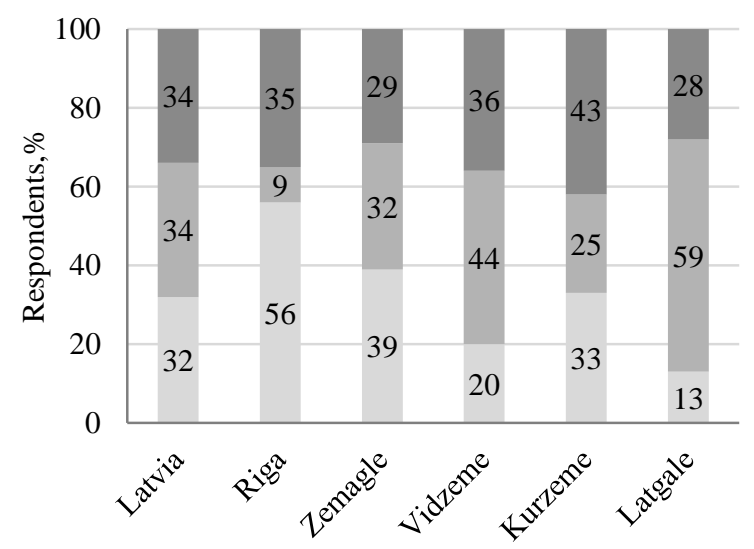

Smart packaging $\square$ Conventional packaging $\square$ I do not care

Figure 4. Respondents' choice between products in smart packaging and in conventional packaging

Figure 4 summarizes the data suggesting that consumers are open to a wider use of innovative packaging for food packaging in Latvia, as 32\% (average in Latvia) and $56 \%$ (in Riga) of respondents are willing to buy such products. Unfortunately, about $30 \%$ of respondents are indifferent to the issue.

Majority of the customers $86 \%$ (in Riga) are ready to see the product in active food packages to extend the shelf life of foods, a small part of respondents (9\%) are willing to see food additives in food products for shelf life extension. Only 4\% respondents have a neutral opinion. It is important to note the buyer's willingness to purchase the product in smart packaging. There is an opposite situation in the areas of Vidzeme (35\%) and Latgale $(37 \%)$, where consumers are not ready to pay more for smart packaging (Figure 5).

The research by Irish scientists also showed that Irish consumers were not willing to pay more for smart packaging (O' Callaghan, Kerry, 2016), but the desire increased after participants were informed about the value of using such technologies.

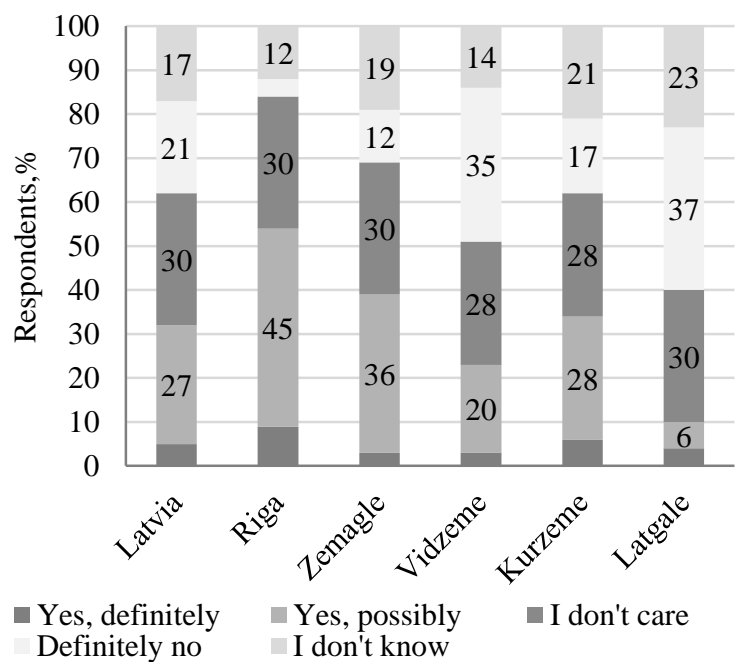

Figure 5. Respondents' readiness to pay a little more for smart packaging 
In Figure 6 we can see that on average in Latvia approximately $6 \%$ of respondents on average in Latvia do not want to pay more for the use of innovative packaging, $23 \%$ are willing to pay up to $5 \%$ more than conventional packaging. In turn, the opinion of respondents in Riga differs significantly from the point of view of the transition respondents in Latvia $-48 \%$ of respondents in Riga would pay up to $5 \%$ more.

The situation has changed in comparison with the previous year on average in Latvia, as the number of consumers who did not want to pay more in 2017 was 29\% (Muizniece-Brasava, Kirse, 2018).

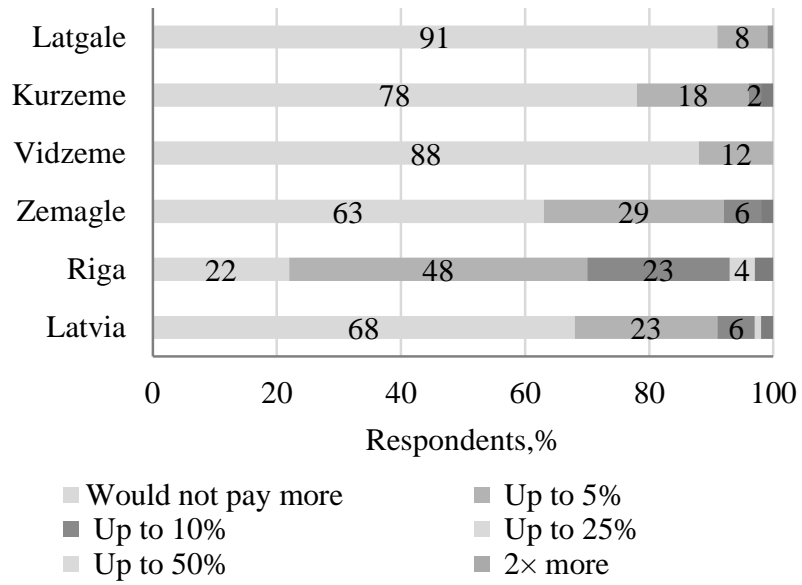

Figure 6. Consumer willingness to pay more for smart packaging compared to conventional packaging

Consumers in a study in the United States expressed readiness to pay more for packages that prolong the shelf life of fresh cut vegetables and wanted to see new types of packaging, such as smart packaging (Wilson et at., 2018).

It is important to note that the respondents, expect to receive additional benefits when thinking about smart packaging (Figure 7) while $56 \%$ of respondents in Riga and $42 \%$ on average in Latvia answered that they were interested in the history of storage conditions of the product.

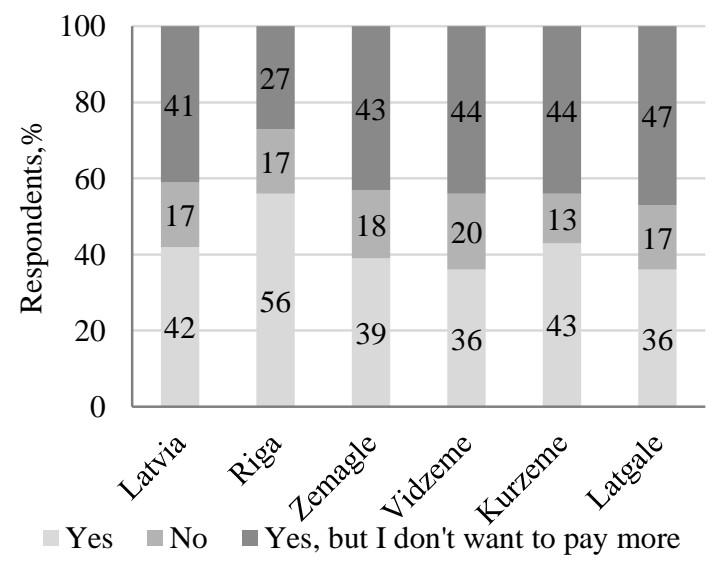

Figure 7. Consumers' interest about history of the storage conditions of the product
The results of the Turkish scientists' study indicated that most of the Turkish consumers' (75\%) expectations from innovative packaging was the visual ability to observe the history and freshness of foods inside the packaging (Aday, Yener, 2015).

In Riga, $53 \%$ of customers are interested in storage conditions, and $47 \%$ are interested in the history of storage of goods. The customers in the Zemgale region are more curious about the history of the storage conditions which is $52 \%$, and $48 \%$ of respondents want to see an extension of the shelf life of goods. The situation in Latgale is entirely different, customers prioritize the shelf life of the product, $62 \%$ of respondents, and $38 \%$ voted for the history of the storage conditions. These voting results reflected the results from Figure 6, in which $91 \%$ of consumers are not ready to pay.

This is justified by lower incomes in this regions average in Latvia. Interest in the correct storage of goods prevails in all regions (Figure 8).

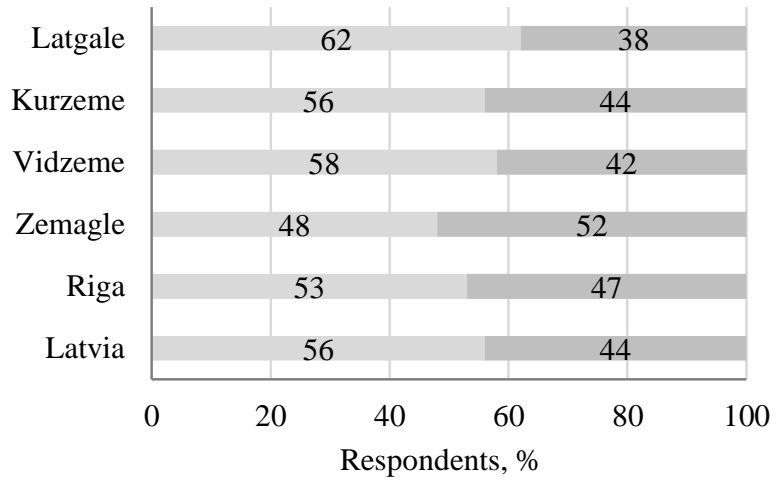

Extended storage term

Opportunity to look at the history of the storage conditions

\section{Figure 8. Customers' expectations from smart packaging}

Analysing the wishes of customers for packaging in more detail shows that an important criterion for the customers is the freshness of the product $54 \%$ in Riga and $57 \%$ in Zemgale (Figure 9).

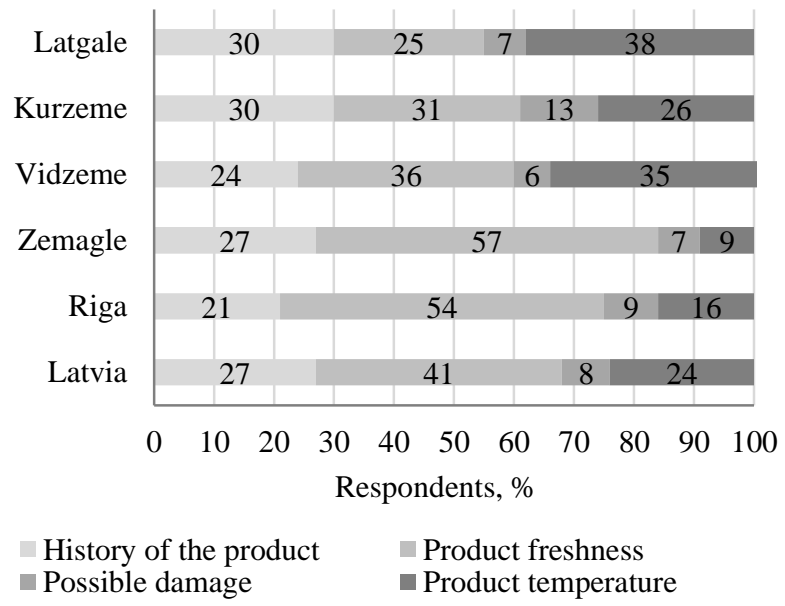

Figure 9. Consumers' opinion on what information should be provided by smart packaging 
The second criterion is the storage history of the product from $21 \%$ in Riga to $30 \%$ in Kurzeme and Latgale. An important criterion for reflected information about the product for the customers is the deterioration of the product $8 \%$ (on average in Latvia). This reflects the following: the staff of the retail stores monitor the goods on the shelf, remove them from the sale in time and the customers do not encounter a spoiled product, or the supplier delivering to the store provides the necessary amount of goods that do not raise the daily sales of the product. An important point in Figure 9 is the increased attention to the desire to receive information about the storage temperature of the product in regions, in comparison with $16 \%$ in Riga to $35 \%$ in Vidzeme and $38 \%$ in Latgale, which could reflect to the failure to store goods at the required temperature.

The application of smart packaging depends upon the product being packaged including food and beverage. It has good potential for use in food and beverage products because of increased demand for diagnostic packaging in response to consumer desire for more information about freshness of foods, product temperature, possible damage, and because of the need for track-and-trace systems.

\section{Conclusions}

The inhabitants of Latvia are little aware of the intelligent packaging and its potential benefits, have little understanding of the new opportunities and new technologies used in the production of packaging in Latvia. But it is important to note that customers are open to new trends, ready to try them, study them and are prepared to pay for smart packaging. Smart packaging has a good potential for use in food and beverage products in response to consumers' desire for more information about freshness and quality of food. Customer introduction to smart packaging must take place through trust, comfort and satisfaction. These three criteria are the basis for perception and willingness to use smart packaging. If the packaging does not carry any additional information for the buyer other than the printed information about the composition of the product, it loses its meaning as being innovative. Such packaging remains only a tool to comply with the minimum requirements for the safety of the goods and the ability to transport them.

\section{References}

1. Aday M.S., Yener U. (2015) Assessing consumers' adoption of active and intelligent packaging. British Food Journal, Vol. 117(1), p. 157-177.

2. Arvanitoyannis I.S., Stratakos A.C. (2012) Application of modified atmosphere packaging and active/smart technologies to red meat and poultry: A review, Food and Bioprocess Technology, Vol. 5(5), p. 1423-1446.

3. Bolumar T., Andersen, M. L., Orlien V. (2011) Antioxidant active packaging for chicken meat processed by high pressure treatment. Food Chemistry, Vol. 129(4), p.1406-1412.
4. Chen Q., Anders S., An H. (2013) Measuring consumer resistance to a new food technology: A choice experiment in meat packaging. Food Quality and Preference, Vol. 28(2), p 419-428.

5. Echegoyen Y., Nerin C. (2013) Nanopracticle release from nano-silver antimicrobial food food containers. Food and Chemical Toxicology. Vol. 62, p. 16-22.

6. Ghaani M., Cozzolino C. A., Castelli G., Farris S. (2016) An overview of the intelligent packaging technologies in the food sector. Trends in Food Science \& Technology, Vol. 51, p. 1-11.

7. Kerry J.P., O'Grady M.N., Hogan, S.A. (2006) Past, current and potential utilisation of active and intelligent packaging systems for meat and muscle-based products: A review. Meat science, Vol. 74(1), p. 113-130.

8. Kuswandi B., Jayus Y.W., Abdullah A., Heng L.Y., Ahmad M. (2011) Smart packaging: sensors for monitoring of food quality and safety. Sensing and Instrumentation for Food Quality and Safety, Vol. 5, p. 137-146.

9. Marsh K., Bugusu B. (2007) Food packaging: Roles, Materials, and Environmental issues. Journal of Food Science, Vol. 72, p. 39-55.

10. Mihindukulasuriya S.D.F., Lim L.T. (2014) Nanotechnology development in food packaging: A review. Trends in Food science \& Technology, Vol. 40, p. $149-167$.

11. Muizniece-Brasava S., Kirse A. (2018) Attitudes of Latvian consumers to traditional and eco-friendly food packaging materials: comparison of 2007 and 2017. In: International scientific conference "Engineering for rural development": proceedings, Jelgava, Latvia, p. 1948-1954.

12. Omanovic-Mikličanin E. (2017) Smart food packaging. In: Journal article; Conference paper: "Work of the Faculty of Agriculture University of Sarajevo”, Sarajevo, Vol. 62, p. 702-708.

13. O' Callaghan K.A.M., Kerry J.P (2016) Consumer attitudes towards the application of smart packaging technologies to cheese products. Food Packaging and Shelf Life, Vol. 9, p. 1-9.

14. Prasad P., Kochhar A., (2014) Active packaging in food industry: A review. Journal of Environmental Science, Toxicology and Food Technology, Vol. 8(5), p. 1-7.

15. Realini C.E., Marcos B., (2014). Active and intelligent packaging systems for a modern society. Meat Science, Vol. 98(3), p. 404-419.

16. Robertson G. (2006) Food Packaging Principles and Practices: Taylor \& Francis, Boca Raton. 733 p.

17. Schafer D., Cheung W.M. (2018), Smart packaging: opportunities and challenges. In: 51st CIRP Conference on Manufacturing Systems. Procedia CIRP 72, p. 1022-1027.

18. Siegrist M. (2008) Factors influencing public acceptance of innovative food technologies and products. Trends Food Science Technologies, Vol. 19(11), p. 603-608.

19. Yam K.L., Takhistov P.T., Miltz, J. (2005) Intelligent packaging: concepts and applications. Journal of Food Science, Vol. 70, p. 1-10.

20. Wilson C.T., Harte J., Almenar E. (2018) Effects of sachet presence on consumer product perception and active packaging acceptability - A study of fresh-cut cantaloupe. LWT-Food Science and Technology, Vol. 92, p. 531-539. 